\title{
Prospective comparison of primary wound closure with tissue- adhesive versus suture materials
}

\begin{abstract}
Rasim Yousif Marbin*
Jalal Hamasalih Fattah*

Abstract

Background and objective: Nowadays the final outcome of wound closure using tissue adhesives and suture material is making a real competition for better results. Cosmetic outcome is regarded as the first demand for the patients. The aim of this study was to make a comparison between the two closure methods in terms of cosmetic outcome, complication and patients' satisfaction.

Methods: A prospective comparative study was conducted at Rizgary Teaching Hospital and West Erbil Emergency Hospital in Erbil city from March 2012 to March 2013. A total of 105 patients were included in the study. The method of closure was selected alternatively between tissue adhesive (octylcyanoacrylate) and suture material. Analysis for cosmetic outcome, complications and patients' satisfaction were done using the statistical package for the social sciences (version 19).

Results: The complications were $25 \%$ (13 patients) in the tissue adhesive group and $18 \%$ ( 9 patients) in the sutured group. Of the 44 patients in the tissue adhesive group, $86.4 \%$ (38 patients) were satisfied; while of the 61 patients in the sutured group, $88 \%$ (54 patients) were satisfied with the end result. Excellent cosmetic outcome achieved in $77.3 \%$ in the tissue adhesive group and $80.3 \%$ in the sutured group.

Conclusion: Tissue adhesive (octylcyanoacrylate) is effective and reliable in primary skin closure, yielding similar cosmetic results to standard suturing method. Tissue adhesive is faster and offers several practical advantages over suture repair.
\end{abstract}

Keywords: Tissue adhesive, cosmetic outcome, complications.

\section{Introduction}

One of the primary goals of wound management is optimal cosmetic outcome. ${ }^{1}$ Techniques to repair lacerations have been around for thousands of years. The first ones documented were 3000 BC in Egypt and consisted of twine, wool, silk, hair and Bengal ants. The first synthetic absorbable was based on polyvinyl alcohol in 1931. Polyglycolic acid was discovered in the 1960s. Tissue adhesives,were first introduced in early 1950's, are currently one known alternative to traditional needle and thread. Tissue adhesives (2 octylcyanoacrylate (OCA), Dermabond, were approved for use in the United States in August 1998. ${ }^{2}$ Tissue adhesives are cyanoacrylate polymers. OCA in low-viscosity and high-viscosity formulas is the only tissue adhesive approved and available commercially in the United States. ${ }^{3,4}$ It is best suited for small, superficial lacerations. OCA polymerizes within 1 minute and begins to peel off in 7 to 10 days. ${ }^{5,6}$ OCA form a strong, durable bond with most human tissues; particularly those tissues containing a large amount of protein, such as skin and tendon. In vitro studies showed that OCA is an effective barrier against the penetration of bacteria. ${ }^{7}$ Tissue adhesive (OCA) may be applied to assist in skin graft placement and stabilization. ${ }^{8}$ Various factors influence the final outcome of scars like direction of scar, wound closure technique, post-operative management, age of the patient, site of the scar, type of skin and race of the patient. ${ }^{5}$ Among the local factors that make the

* Department of plastic surgery, college of medicine,Hawler medical university, Erbil, Iraq. 
wound problematic are ischemia, pressure, radiation, foreign material, and bacterial contamination. $^{6}$ Tissue adhesive offer many potential advantages over standard wound closure, including ease of use, decrease in pain and time to apply, requires less skills, it acts as skin, allowing for flexibility, waterproofs after drying time of two hours. It may improve the patient comfort as there is no need for injecting a local anesthetic specially in children as well as not requiring a follow up visit for suture removal. ${ }^{9-13}$ The drawback of these materials includes; process of polymerization gives off heat and can give off toxic gases that is irritant to eyes and lungs, ${ }^{14,15}$ the adjustment of the edges of the wound in younger patients are less successful than with thin sutures, ${ }^{16}$ and they are relatively expensive. ${ }^{17}$ It is utilized solely for the closure of epidermal edges, entrance into the wound itself may impede wound healing or result in foreign body reaction. ${ }^{8,18}$ Its use for larger incisions is less common, ${ }^{19}$ and tissue adhesive does not support significant skin edge tension during healing. ${ }^{20}$ Contraindications to use of skin adhesives are jagged or stellate lacerations, bites, punctures, crush wounds, contaminated wounds, mucosal surfaces, axillae and perineum (highmoisture areas), hands, feet and joints (unless kept dry and immobilized). ${ }^{4}$ Selection of OCA for skin closure is regarded as a new technique in our country and as it has characteristics that made it most favorable method for wound closure, therefore we selected this subject to make the advantages and disadvantages of OCA more obvious compared with traditional suturing techniques. The aim of this study was to assess the final outcomes of primary wound closure with tissue adhesives in comparison with suture materials in terms of cosmetic outcome, complications, and patient's satisfaction.

\section{Methods}

Design and sample collection: This is a prospective comparative study conducted in Erbil city, Kurdistan region-Iraq in the Department of Plastic and Reconstruction Surgery in Rezgary Teaching Hospital and West Erbil Emergency Hospital (WEEH) from March 2012 to March 2013. A total of 105 patients were included in this study of which 44 were closed with OCA and 61 were closed with suture. The differences between the number of two groups was due to inability to apply the OCA in some patients who refused to apply chemicals to their wound and in irritable children. The method for collection of the sample was by alternative patient selection, first by using tissue adhesive and next by using suture technique. Fortunately there was no loss of patients' follow up and all enrolled patients in the study were continued follow up although it was irregular in some patients.

Exclusion criteria: The exclusion criteria in this study included wounds unsuitable for closure like bite, stellate, crush wounds, wounds greater than 8 hours duration, wounds involving the vermillion border, mucosal surface, ear or hairline, wounds in immunocompromised or keloid former patients, and over movable region.

Mechanism of action of OCA: As the adhesive moves through the applicator tip, it mixes with an initiator and begins the chemical change from monomer to polymer. Moisture on the skin's surface adds the final catalyst to create the strong polymer bond that bridges the wound edges.

\section{Procedure:}

A detailed history was taken and full examination was done for all patients. All wounds have been prepared for closure after irrigation and debridement and detailed measurements done for every wound (a simple ruler was used for the purpose of measurement), antiseptic put then closed either in one layer or in double layers. The superficial wounds were closed in one layer while the deeper wound closed in two layers (deep layer sutured by absorbable suture (polyglycolic acid II) using numbers $4-0,5-0$ or $6-0$ in USP rating system according to anatomical 
region and superficial layer closed with tissue adhesive (OCA) or by non-absorbable sutures (polypropylene) numbers 4-0, 5-0 or 6-0. The technique that used for suturing was simple interrupted suture, then topical antibiotic and dressing were put for wounds closed with suturing versus OCA which doesn't need topical antibiotic neither dressing. The OCA was applied to wounds in a standard manner. The wound edges were held for a minimum of 30 seconds to allow polymerization. This adhesive reaches maximum bonding strength within 2.5 minutes and is equivalent in strength to healed tissue at seven days post repair. No dressing was applied systemic antibiotic given for every patient following procedure, and instructions were given for all of them. The follow up was scheduled for patients, in $3^{\text {rd }}$ day, 1 week, 1 month, and 3 months. Data were collected on a standardized questionnaire. The follow up findings were reported and analyzed, photographs have been taken for all patients in each visit and complications were reported for both group and managed accordingly. Then, every patient as asked about his/ her satisfaction about the end result of the scar in the form of satisfied to result or not, a hand mirror was used for that purpose. The assessment of scars was performed by the surgeon, and Vancouver scar grading scale, ${ }^{12}$ was used for grading of the scars and the surgeon assessment were excellent for grades of $0-4$ and accepted for grades of 5-9 and bad for grades of 10-14.

Ethical considerations: The study protocol was approved by Medical Ethics Committee of the College of Medicine of Hawler Medical University. Informed consent obtained from all adult patients prior to participation in the study. For children below 18 years old, the consent was obtained from the parents. The purpose of the study was carefully explained to each participant. All selected patients were cooperative and agreed to participate in the study.
Statistical analysis: Data were analyzed using the statistical package for the social science (version 19). Chi square test of association was used to compare between proportions. Fisher exact test was used when the expected count of more than $20 \%$ of the cells of the table was less than 5. A $P$ value $\leq 0.05$ was considered statistically significant.

\section{Results}

Of 105 patients presented to the WEEH and Rizgary Teaching Hospital, 44 wounds were closed with OCA while 61 wounds were closed with suture. The ages ranged between 8 months and 73 years with the mean age of 36.9 years (Table 1 ).

Table 1: Distribution of the patients according to the age groups.

\begin{tabular}{lll}
\hline $\begin{array}{l}\text { Age group } \\
\text { ( Years) }\end{array}$ & Number & $\%$ \\
\hline$<10$ & 43 & 44.8 \\
$11-20$ & 12 & 11.4 \\
$21-30$ & 20 & 19 \\
$31-40$ & 12 & 11.4 \\
$>40$ & 14 & 13.4 \\
Total & 105 & 100 \\
\hline
\end{tabular}


http://dx.doi.org/10.15218/zjms.2015.0003

Complications occurred in 22 patients $(21 \%)$ among the total of 105 patients as shown in Table 2. The proportion of complications were higher among OCA group (25\%) than the suturing group (18\%), but this was statistically not significant $(P=0.387)$ as shown in Table 3.
However not all complications were significant clinically as most of complications (20 patients, $90.9 \%$ ) got excellent cosmetic outcome (an example is shown in Figure 1 ), a single patient (4.5\%) got accepted cosmetic outcome (Figure 2).

Table 2 : The frequency of complications.

\begin{tabular}{llllllllll}
\hline Complcations & infection & Dehiscence & Hematoma & $\begin{array}{l}\text { Wide } \\
\text { scar }\end{array}$ & $\begin{array}{l}\text { Depressed } \\
\text { scar }\end{array}$ & $\begin{array}{l}\text { Hypert. } \\
\text { scar }\end{array}$ & $\begin{array}{l}\text { Trap- } \\
\text { door }\end{array}$ & Pigmentation & Total \\
\hline No & 3 & 4 & 1 & 9 & 1 & 2 & 1 & 1 & 22 \\
$\%$ & 2.85 & 3.8 & 0.95 & 8.57 & 0.95 & 1.9 & 0.95 & 0.95 & 20.95 \\
\hline
\end{tabular}

Table 3: Complication in relation to closure methods

\begin{tabular}{llll}
\hline & Complication number & Complication \% & $\mathbf{p}$ \\
\hline OCA \% & 13 & 25 & 0.387 \\
Suture \% & 9 & 18 & \\
\hline
\end{tabular}

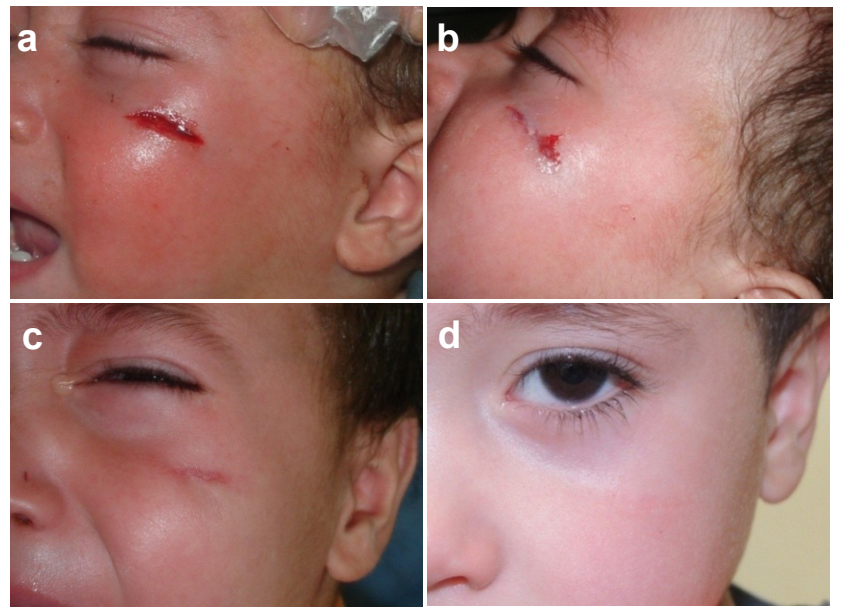

Figure 1: a- Laceration in It cheek by sharp trauma. b- Post closure with OCA. c- after one week (wide scar). d-Three months follows up visit example of excellent result.
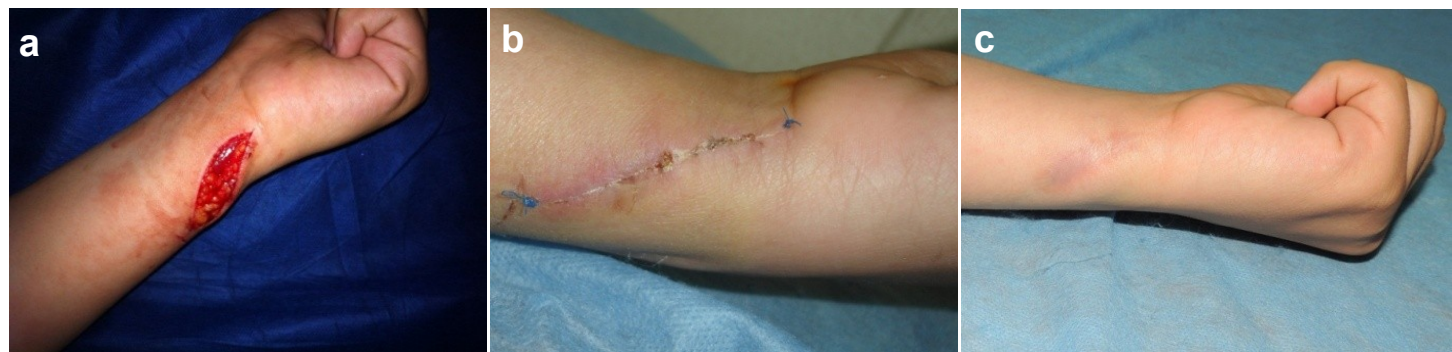

Figure 2: a- lacerated wound in ulnar aspect of left forearm due to sharp injury managed by suturing. b- after 1 week. c- Wide scar, example of accepted result after 3 months follows up visit. 
And a single patient (4.5\%) got bad cometic outcome (Figure 3). The percentage of total satisfaction in this study was high $87.6 \%$ (Table 4).Presence of complications was significantly associated with satisfaction $(P<0.001)$ as shown in Table 5 . The majority of patients in both groups got accepted to excellent cosmetic outcome $(P=0.686)$ as shown in Table 6.
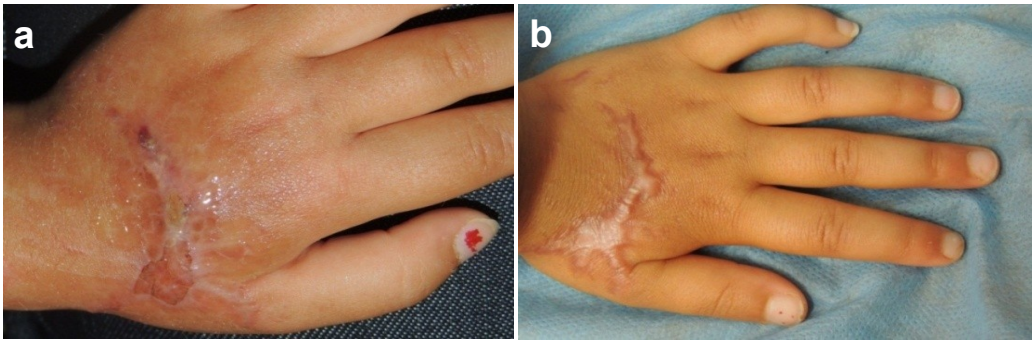

Figure 3: a- Laceration on the dorsum of It hand, closed by OCA. b- Hypertrophic scar after 3 months follows up visit, example of bad result.

Table 4: The total satisfaction rate.

\begin{tabular}{lll}
\hline Patient satisfaction & No & $\%$ \\
\hline Satisfied & 92 & 87.6 \\
Not satisfied & 13 & 12.4 \\
Total & 105 & 100 \\
\hline
\end{tabular}

Table 5: The relation between complication and patients' satisfaction.

\begin{tabular}{cccccccc}
\hline \multirow{2}{*}{ Complication } & \multicolumn{2}{c}{ Not satisfied } & \multicolumn{2}{c}{ Satisfied } & \multicolumn{2}{c}{ Total } & \multirow{2}{*}{ P value } \\
& No & $\%$ & No & $\%$ & No & $\%$ & \\
\hline No & 1 & 1.2 & 82 & 98.8 & 83 & 100 & \\
Yes & 12 & 54.5 & 10 & 45.5 & 22 & 100 & $<0.001$ \\
Total & 13 & 12.4 & 92 & $87.6 \%$ & 105 & 100 & \\
\hline
\end{tabular}

Table 6: Cosmetic outcome in relation to closure methods.

\begin{tabular}{llllllllll}
\hline Closure & \multicolumn{4}{l}{ Cosmetic outcome } & \multicolumn{3}{c}{ P value } \\
method & \multicolumn{2}{c}{ Excellent } & \multicolumn{2}{c}{ accepted } & \multicolumn{2}{c}{ Bad } & \multicolumn{2}{c}{ Total } & \\
& No & $\%$ & No & $\%$ & No & $\%$ & No & $\%$ & \\
\hline OCA & 9 & 20.5 & 34 & 77.3 & 1 & 2.3 & 44 & 100 & 0.686 \\
Suture & 12 & 19.7 & 49 & 80.3 & 0 & 0 & 61 & 100 & \\
Total & 21 & 20 & 83 & 79.1 & 1 & 0.9 & 105 & 100 & \\
\hline
\end{tabular}




\section{Discussion}

The cosmetic outcome of wound considered as a main goal of patients. The OCA preferred among all other available tissue adhesives as it had been FDA approved in 1998 and it is less toxic, more flexible and it had designed to address the limitations of the butyl-2-cyanoacrylate as the OCA has four times the breaking strength of buytl-2-cyanoacrylate. This study revealed that there were no statistically significant differences in the complication rates between both groups (25\%) for OCA and $(18 \%)$ for suture group $(P=0.387)$. Although the number of complications (22 patients) seems to be high, however most of the complications were minor and associated with high patients' satisfaction. The result of this study is consistent with the study done by Handschel et al as they stated that no significant complications were observed in any groups. ${ }^{14}$ This small difference in the percentage $(25 \%$ and $18 \%$ ) could be due to ignorance of the patients for the instructions about this adhesive material. In fact, immediately after wound closure, skin sutures provide a more secure closure, as measured by breaking strength, than do tissue adhesives. However, seven days later, the breaking strengths of wounds closed by tissue adhesives did not differ significantly from those repaired with percutaneous sutures. ${ }^{13}$ In this study, no significant differences were shown for dehiscence in contrast to the study done by Coulthard et al that showed an increased risk of dehiscence with tissue adhesives compared with suture. $^{21}$ Although 4 patients (3.8\%) developed dehiscence but no revision were necessary. A high percentage of satisfaction were achieved in both groups $(87.6 \%$ of OCA and $88.5 \%$ of suture group) with no statistically significant difference which was an encouraging point to use OCA instead of suture, as it is easy to apply, painless, less time consuming, less equipment needed, no anesthesia, no dressing and no topical antibiotic application were needed. Our result is consistent with the study of Holger et al, ${ }^{1}$ Bruns, ${ }^{4}$ and Coulthard et al, who found that; there were no significant differences between tissue adhesives and sutures for wound closure regarding incidence of dehiscence, infection, and satisfaction with the cosmetic appearance when assessed by patients' or surgeons' satisfaction. ${ }^{21}$ There were some problems that we faced in our study like unavailability of OCA in our country and the way of obtaining this material was for some extent difficult (by post) which had a direct effect on reducing the sample size. In addition, the way of contact with patients was limited because of neglection of the patients for the follow up visit or taking care about the wound hygiene, inappropriate protection from sun, in addition to that some patients were coming from countryside that made their visit irregular, which might have a direct effect in increasing the rate of complications.

\section{Conclusion}

Octylcyanoacrylate is effective and reliable in skin closure for emergency and elective surgical wounds, yielding similar cosmetic results to standard suture. OCA is faster and offers several practical advantages over suture repair for patients. The use of tissue adhesive for wound closure instead of traditional suture material is preferred and is highly recommended in pediatric age group. We advise further study on this material on larger sample size and recommend the ministry of health to provide this helpful and useful material for the regional hospitals especially the emergency and plastic surgery departments.

\section{Conflicts of interest}

The authors report no conflicts of interest.

\section{References}

1. Hogler JS, Wandersee SC, Hale DB. Cosmetic outcomes of facial lacerations repaired with tissue-adhesive, absorbable, and non-absorbable sutures. AJEM 2003; 22(4): 254-5. 
2. Elmore J, Smith E, Kirsch A. Sutureless Circumcision Using 2-Octyl Cyanoacrylate (Dermabond):Appraisal After18-Month Experience. Urology J 2007; 70 : 294-9.

3. Beam JW. Tissue Adhesives for Simple Traumatic Lacerations. J Athl Train. 2008; 43(2): 222-4.

4. Bruns TB, Worthington JM Using tissue adhesive for wound repair: a practical guide to dermabond, Am Fam Physician 2000; 61(5):1383-8.

5. Kumar P., Basic principles and techniques of plastic surgery. Hyderabad, Paras medical publisher, $1^{\text {st }}$ ed., 2001. 1: 24-6.

6. Weinzweig J. Plastic surgery secrets. Elsevier: $2010,2^{\text {nd }}$ ed.; 29-33.

7. Brown J, Campbell B, Drongowski R . A prospective, randomized comparison of skin adhesive and subcuticular suture for closure of pediatric hernia incisions: cost and cosmetic considerations. Journal of Pediatric Surgery 2009 ; 44: 1418-22.

8. Kaminer S, Arndt A, Dover S, Rohrer E, Zachary B. Atlas of cosmetic surgery. Elsevier; $2^{\text {nd }}$ ed.; 2009. 1: 408.

9. Singer AJ, Kinariwala M, Lirov R, Thode HC. Patterns of use of topical skin adhesives in the emergency department. Acad Emerg Med 2010; 17(6):670-2.

10. Chung C, Rudkin G. Lacerations. Greer S., Benhaim P., Lorenz H., Chang J., Hedrick H. Handbook of plastic surgery. Marcel Dekker; 2004. $1^{\text {st }}$ ed.; 114-7.

11. Farion $\mathrm{K}$, Osmond $\mathrm{MH}$, Hartling $\mathrm{L}$, Russell $\mathrm{K}$, Klassen T, Crumley E, et al. Tissue adhesives of traumatic lacerations in children and adults. The Cochrane Library 2002; (3):223-7.

12. Stephen J. Mathes. Plastic surgery. SaundersElsevier. 2006; $2^{\text {nd }}$ ed. $1 ; 222-3$.

13. Noordzij J, Foresman P, Rodeheaver G, Quinn J, Edlich $\mathrm{R}$. Tissue adhesive wound repair revisited. JEM. 2008; 12 (5):645-9

14. Handschel J G, Depprich R A, Dirksen D, Runte C, Zimmermann A, Kübler N R. A prospective comparison of octyl-2-cyanoacrylate and suture in standardized facial wounds. Oral And Maxillofacial surgery $2001 ; 137(9): 1177-80$.

15. Perry AW. Severe Allergic Reaction to Dermabond, ASJ. 2009 ; 29: 314-6.

16. Greene D R, Koch JK, Goode RL. Efficacy of octyl-2-cyanoacrylate tissue glue in blepharoplasty. Archives of facial plastic surgery 1999; 1(4):292-6.

17. Strauss E, Weil W, Jordan C, Paksima N. A Prospective, Randomized, Controlled Trial of 2-Octylcyanoacrylate Versus Suture Repair for Nail Bed Injuries. JHS 2008 ; 33 (2) : 250-3.

18. Dragu $F$, Schwartz S, Beier $P$, Kneser $U$, Bach D, Horch E. Foreign body reaction after usage of tissue adhesives for skin closure: a case report and review of the literature. Archives of Orthopaedic and Trauma Surgery 2009; 129 (2):167-9.
19. Rimmer J, Singh A, Banwell P, Clarke PM, Evans PR. The Use of Octyl-2-Cyanoacrylate (Dermabond $^{\mathrm{TM}}$ ) Tissue Adhesive for Skin Closure in Head and Neck Surgery. ARSE 2006; 88(4): 412-3.

20. Jeffrey J. Essentials of plastic surgery. Karen Berger; 2007; $1^{\text {st }}$ ed. 1: 16-19.

21. Coulthard PE, Esposito M, Worthington HV, van der Elst $M$, van Waes OJ, DarceyJ. Tissue adhesives for closure of surgical incisions. The Cochrane Library. 2010; 12 (5):345-8. 